\title{
Diagnostics of hydraulic density of plunger couple of tractor diesel
}

\author{
Tatyana Bodyakina ${ }^{1,{ }^{*}}$, Petr Boloev ${ }^{2}$, Mihail Buraev ${ }^{1}$, and Alexey Shisteev ${ }^{1}$ \\ ${ }^{1}$ Irkutsk State Agricultural University named after A.A. Ezhevsky, 664038, Irkutsk region, Irkutsk \\ distrikt, Molodezhny settlement, Russia \\ ${ }^{2}$ Buryat State University named after D. Banzarov, 24a, Smolin st., 670000, Ulan-Ude, Russia
}

\begin{abstract}
The article considers the process of developing diagnostic mathematical models that take into account the influence of the hydraulic density of the plunger pair associated with wear. To estimate leaks of precision parts, methods for calculating the cycle feed for wear of plunger pairs are presented. The position of the cut-off edge relative to the hole changes due to the injection movement and rotation of the plunger during the regulation of the fuel cycle. The method and results of accelerated testing of plunger pairs are also presented.
\end{abstract}

\section{Introduction}

The ability to conduct maintenance, diagnose the main elements of military equipment, which include the power plant. One of the main components of the power plant is the fuel system.

The main unit of the diesel fuel system is a high pressure fuel pump. Work on dosing the amount of injected fuel in the high-pressure fuel pump performs a plunger pair (PP). In the production of PP, the strict geometry of the precision surfaces of the plungers and bushings is observed. The size of the gap in the pair is ensured by pair grinding. In the process of technical operation, the main unit that determines the level of functional reliability of the injection pump is PP. On average, about $80 \%$ of the total number of faulty PPs are rejected due to wear of precision surfaces. The main reason for wear is abrasive particles that enter the supraplunger space and into the gap between the plunger and the sleeve during disassembly of the injection pump assembly. Depreciation leads to a loss of hydraulic density and, as a consequence, to problems such as difficulty starting the diesel engine, deterioration of the working process in the cylinder, and dilution of oil by fuel [1].

Numerous studies have shown that the effect of PP wear on fuel leaks between its precision surfaces is sharply non-linear [2]. A significant part of the PP life cycle is accompanied by insignificant wear and tear, which practically does not affect the nature of fuel injection and the working process of the diesel engine as a whole.

To prevent failures and downtime of the machine and tractor fleet, it is necessary to eliminate the problems and causes that occur when using two types of fuels. The fuel supply depends mainly on the wear of the plunger pairs, so we selected it for research.

*Corresponding author: Bodt-24@rambler.ru 
Wear of the plunger pairs affects the uneven supply and changes in the fuel and energy indicators of the diesel engine. Also, the wear of the plunger pairs affects the start of the feed and its duration. Changing the fuel supply, uneven distribution across the cylinders disrupts the combustion process of the fuel mixture, the engine works rigidly with a smoky exhaust and with more intensive wear of the connecting rod-piston group parts. The purpose of the study is to determine the hydraulic density of plunger pairs in an experimental study on two types of fuels. Object of research: the process of wear of plunger pairs $[3,4]$.

Studies conducted by Voronin D.M., Dobrolyubov I.P., Zmanovsky V.A., Zmanovsky V.A., Zuev V.A., Livshits V.M., Natarzan V.M., Nikolaenko AB, Pavlov B.V., Plaksin AM, Savchenko O.F., Khabardin V.N. and others, show that malfunctions arising in fuel equipment lead to a decrease in the power of ICE by $15 \%$ and an increase in fuel consumption by $20 \%$.

To control the technical condition of the diesel fuel equipment, methods and tools are used that allow for diagnostic and diagnostic operations with both partial disassembly of the TA and CIP. CIP methods have established themselves as universal and operational, allowing a comprehensive assessment of the state of precision TA units.

It has been established that gaps in precision vapors and the magnitude of the pressure at the beginning of fuel injection have a significant effect on the characteristic of the injection pressure.

\section{Materials and discussion}

The main criterion for the quality of precision pairs is the hydraulic density, characterized by the time of leakage of liquid or air under a certain pressure into the gap of the plunger pair.

At enterprises, the density of plunger pairs is the main criterion for assessing their technical condition. Estimate the density during hydraulic pressure testing of steam under static pressure on special devices [5].

With the wear of the plunger pairs, their macro- and microgeometry change significantly, thereby changing the size and shape of the gap. Abrasively worn surfaces have significant irregularities and indentations in the form of scratches and grooves forming micro channels. Due to this, the size increases and the shape of the gap in the interface of the plunger and the sleeve changes. All of these factors are the result of plunger pair wear.

The clearance in the mating plug-bush may be a criterion for assessing the technical condition of the plunger pairs of fuel equipment. It depends not only on local areas of wear, but also on mounting deformations, fuel pressure. This causes a significant non-uniformity of the gap along the length of the plunger pair and makes its measurement practically impossible $[6,7]$.

Determining the clearance in the plunger couples is a very time-consuming operation, requiring complex instruments of high accuracy and highly qualified staff. However, the presence of gaps in the plunger pairs does not fully characterize their sealing properties, especially with local wear. This is because the gap is determined only in some places or zones of the precision surfaces of the plunger and sleeve, and the sealing properties of the plunger pair depend on the quality and degree of wear of the entire working surface of the part, which is very difficult to evaluate. Therefore, the technical condition of plunger couples is evaluated by various methods using complex indicators.

A distinctive feature of the wear of plunger pair parts is the concentration of wear on individual surface areas. In the liner, wear sections are concentrated above the inlet and from the lower side of the bypass windows. For the plunger, local wear is located in the surface zones that are combined when working with the indicated wear sections of the liner, 
that is, in the section adjacent to the inlet window and at the cut-off edge in that part where the bypass window opens when the feed is cut off $[8,9]$.

The location of the areas of local wear on the surfaces of the plunger and the sleeve coincides with the zones of the most intense leakage of fuel through the gaps during injection and its flow into the windows at the initial and final moments of injection. This fact indicates a relationship between the wear of plunger couples and the flow of fuel.

For operational diagnostics, methods are required for non-disassembly of operational fixation of measurement signals of aggregates without their disassembly and removal from the engine. Application of simulation methods for integral characteristics taking into account possible defects and misalignments. To assess the technical condition of the fuel equipment, the role of this characteristic can be played by the pressure diagram in the highpressure tube [10].

When developing diagnostic mathematical models of an object, special attention should be paid to accurately describing the impact of the hydraulic density of the plunger pair associated with wear.

It is known from the literature analysis and previously performed experimental studies that the methods based on the Zhukovsky hydraulic shock model are most widely used in the mathematical description of processes in fuel equipment.for the practical implementation of this method, it is necessary to choose a method for solving the wave equation taking into account the boundary conditions for each considered section of fuel movement $[11,12]$. To describe the boundary conditions, quantitative accounting for the leakiness of the plunger pair is possible when a component that takes into account the flow of fuel through the gaps in the plunger pair is included in the flow continuity equation:

$$
d V_{p}-d V_{c}-d V_{o}-d V_{k}-d V_{v m^{-}}-d V_{l p}-d V_{l v}=0,
$$

where $d V_{p}$ - is an elementary volume change of the fuel by displacement of the plunger; $d V_{c}$ - a basic change of the fuel volume as a result of the compressibility of the fuel; $d V_{o}$ - a basic change of the amount of fuel in the result of the expiry using the filling hole when they are open; $d V_{k}$ - change basic fuel amount in the result of the expiration of the fuel through the open discharge valve; $d V_{v m}$ - a basic change of the fuel volume as a result of moving the discharge valve; $d V_{l p}$ - a basic change of the fuel volume as a result of fuel leaks through gaps in the piston pair; $d V_{l v}$ - basic changes in the amount of fuel leakage of fuel through leakage of the injection valve.

$$
d V_{l p}=Q d t
$$

where $Q$ - is the volumetric fuel consumption due to the leakiness of the plunger pair. To evaluate leaks that occur when precision parts are low in water density, we used methods for calculating the cycle feed for wear of plunger pairs.

To determine the fuel consumption due to the leakiness of the plunger pair, formulas based on the law of the poiseil pressure loss were used. For the case of a narrow eccentric ring gap, it is $Q, \mathrm{~m}^{3} / \mathrm{s}$ defined as [13]

$$
Q=\frac{\pi \cdot d_{\Pi} \cdot \delta^{3}}{12 \cdot \mu_{\mathrm{T}} \cdot l} \cdot\left(1+\frac{3}{2} \cdot \frac{\varepsilon^{2}}{\delta^{2}}\right) \cdot \Delta p
$$

where-the diameter of the plunger; - the radial clearance; - the coefficient of dynamic viscosity of the fuel; - the length of the seal cylinder, the eccentricity; - the pressure drop in the seal.

For large differences, and when working with fuel equipment, it reaches several tens of $\mathrm{MPa}$, it is necessary to take into account the variability along the gap of the dynamic coefficient of viscosity of the fuel from the equation 


$$
\mu_{\mathrm{T}}=\mu_{\mathrm{TO}} \cdot e^{b p},
$$

where $\mu_{\mathrm{TO}}$ viscosity at zero overpressure, for diesel fuel was accepted $\mu_{\mathrm{T} 0}=3,8$. $10^{-3} \frac{N \cdot S}{m^{2}} ; p$ - fuel pressure, MPa.

Coefficient values $b$ based on experimental data for diesel fuel $b \approx 0,0025$.

Equation (3) is applicable for the piston part of a plunger pair with a seal length of $l_{\Pi}=60 \mathrm{~mm}$ and the flow of fuel into a drainage line with atmospheric pressure $\Delta p=p_{\mathrm{H}}$.

For the spool part of the plunger with a longitudinal outer channel, use the formula for a flat slot that takes into account the flow of fuel through the cut-off hole.

$$
Q=\frac{\delta^{3} \cdot \Delta p \cdot b_{g w}}{12 \cdot \mu_{\mathrm{T}} \cdot l_{o}},
$$

where $b_{g w}$ - the width of the gap; $l_{o}$ - the path of fuel from the over-plunger cavity to the cut-off hole.

Given that the position of the cut-off edge relative to the hole changes due to the injection movement and rotation of the plunger in the process of regulating the cyclic fuel supply.

Therefore, the problem is reduced to determining the shortest path from the hole axis to the preventive section of the spool for all possible positions of the plunger during operation of the pump.

From equations (3) and (5), the dependence of the volume flow rate can be represented by the equation

$$
Q=\frac{\pi \cdot d_{p} \cdot \Delta P \cdot \delta_{R \max }^{3}}{12 \cdot v_{\mathrm{T}} \cdot l_{p} \cdot \rho_{\mathrm{T}}} \cdot \frac{\alpha}{360},
$$

where $d_{p}$ - the diameter of the plunger; $\Delta P$ - a differential pressure in the seal; $\delta_{R \max }$ the maximum radial clearance; $v_{\mathrm{T}}-$ is the kinematic viscosity of the fuel; $l_{p}$ - the length of the working surface of the piston; $\rho_{\mathrm{T}}-$ is the density of the fuel; $\alpha$ - arc corner surface of the plunger exposed to the highest local wear.

Analysis has shown [14] when selecting the size of the gap between the plunger and the sleeve $\delta_{\mathrm{T}}$, consider the technological gap increase due to wear $\delta_{w}$, increasing the gap as a result of the oval shape of the plunger and the sleeve $\delta_{0}$, due to the longitudinal grooves $\delta_{P}$ and deformation of the plunger and the sleeve caused by the pressure of the fuel $\delta_{K}$. The total gap can be represented as a dependency

$$
\delta=\delta_{\Sigma}+c \cdot p
$$

where $c-$ is the coefficient that characterizes the geometry and material of the plunger pair [1]; $\delta_{\Sigma}=\delta_{T}+\delta_{w}+\delta_{0}+\delta_{P}+\delta_{K}$.

For practical calculations $\delta_{\Sigma}$, it ranges from 1.2 microns for a new plunger pair to 20 microns for a worn one.

During the simulation of the fuel supply process, fuel leaks that occur during wear of precision assemblies were identified.

\section{Results and discussion}

As a result of the simulation of the fuel supply process, it was found that one of the parameters for monitoring the state of precision TA units can be the registration of pressure changes in the fuel injection line, depending on the angle of rotation of the camshaft of the injection pump or the crankshaft of the internal combustion engine [15]. In this case, the 
maximum fuel supply to the internal combustion engine cylinders should be ensured. Under operating conditions, the maximum fuel supply is carried out when the diesel is fully loaded or in the mode of its free acceleration from minimum to maximum crankshaft speed, when the engine is fully loaded by inertia. Therefore, as a test mode, the diesel free acceleration mode can be used. As diagnostic parameters, it is proposed to use the change in the cyclic fuel supply from the time of the experimental study obtained in the field of starting and nominal rotation speeds of the crankshaft of a diesel engine.

To check the adequacy of the proposed method, an experiment was conducted, the purpose of which was to obtain an experimental characteristic of the cyclic feed in time.

To determine the size of leaks when using the types of fuels under consideration, the test bench for testing and adjusting fuel equipment of the Ki-22205-01 brand was upgraded. Fuel leaks were determined at starting, $n=100 \mathrm{~min}^{-1}$, and at nominal, $n=1100 \mathrm{~min}^{-1}$ [16].

For this purpose, accelerated wear tests of the UTN-5 fuel injection pump were carried out on a modernized stand for testing and adjusting fuel equipment. During accelerated wear tests, the operating conditions are reproduced, and the wear rate is increased by tightening the operating mode. The latter allows you to reduce the time of the experiment and get reliable results.

The methodology for conducting accelerated tests of fuel injection systems of tractor and combine diesels for reliability was developed in the Central research Institute AND is given in the industry standard OST 23.1.364-81 [10]. According to this standard, such tests are carried out to determine the resource of fuel pumps in the Assembly, as well as their individual components, aggregates and parts. The standard is mandatory for manufacturers of fuel equipment for tractor and combine diesels for systematic random inspection of the produced fuel equipment $[6,9,12]$.

To measure this value, the Ki-22205-01 stand was upgraded and an abrasive was added to the fuel for an accelerated experiment. During the process, data was recorded in the log.

The rail on the fuel pump must be secured to prevent it from moving.

The temperature of the fuel and mixture should be the same within $60^{\circ}-80^{\circ} \mathrm{C}$, while the viscosity of diesel fuel and water biofuels is the same $(1,64 ; 1,68)$. Leaks are calculated from the difference between the theoretical volume of the loop feed and the actual feed:

$$
V_{l}=V_{p}-V_{c f},
$$

where $V_{p}$ - the theoretical fuel supply volume is determined by the formula (9); $V_{c f}$ - the actual cycle supply.

$$
V_{p}=\frac{\pi \cdot d^{2} \cdot h}{4}
$$

Before the tests, the hydraulic density of the plunger pairs, discharge valves and sprayers was checked, and, in accordance with the current technical conditions, the TNVD UTN was adjusted-5 $[5,10,15]$. To ensure the same initial test conditions, the fuel pump was equipped with precision parts and high-pressure fuel lines of the same hydraulic density and throughput.

The total duration of the experiment was 60 hours for each type of fuel. During testing, fuel samples were contaminated with fine quartz micro-powders according to GOST 364780 [3] with a grain size of $m$ to a concentration of $0.0125 \mathrm{~g} / 1$.

Experimental data are presented in figures 1 and 2. 


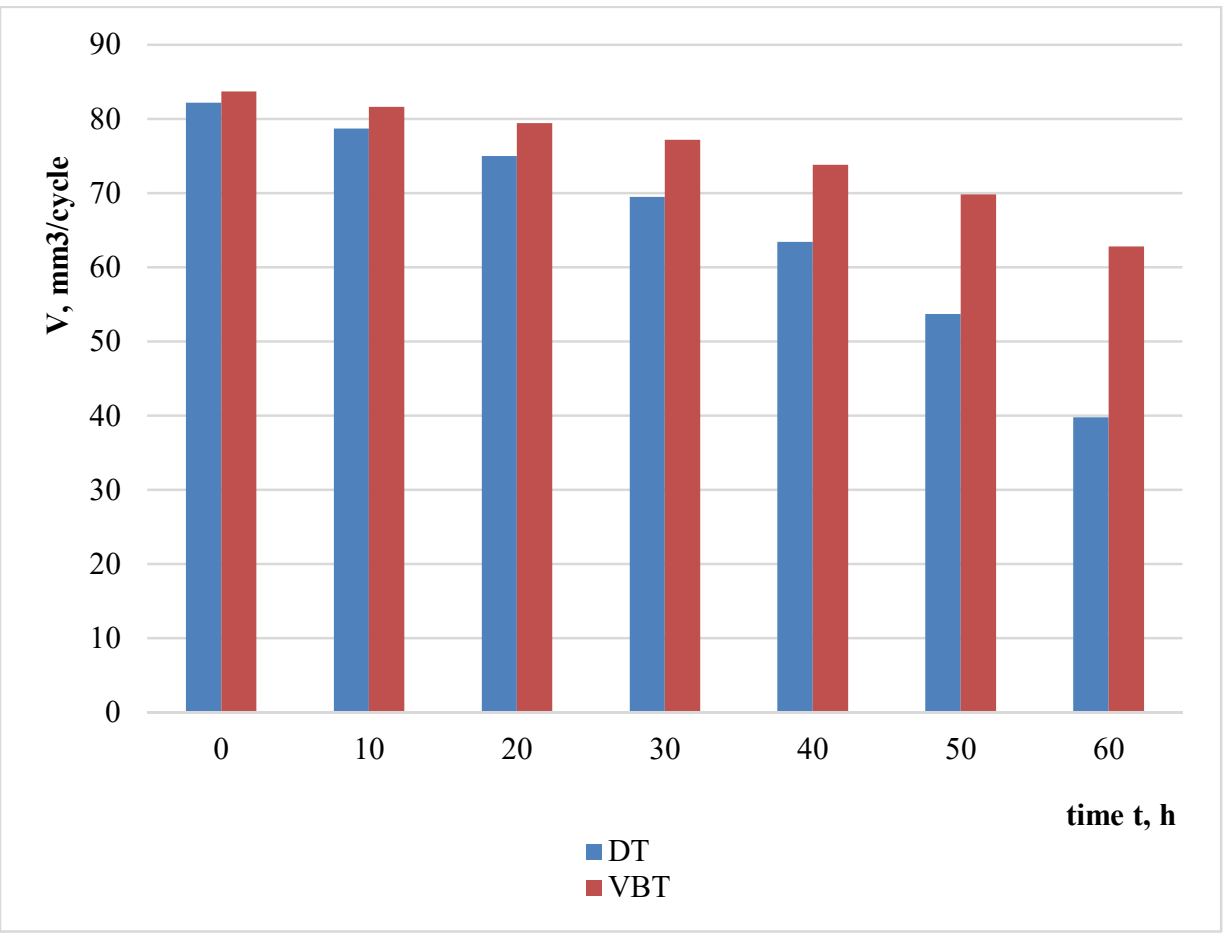

Fig. 1. Changing the fuel cycle in the start-up mode.

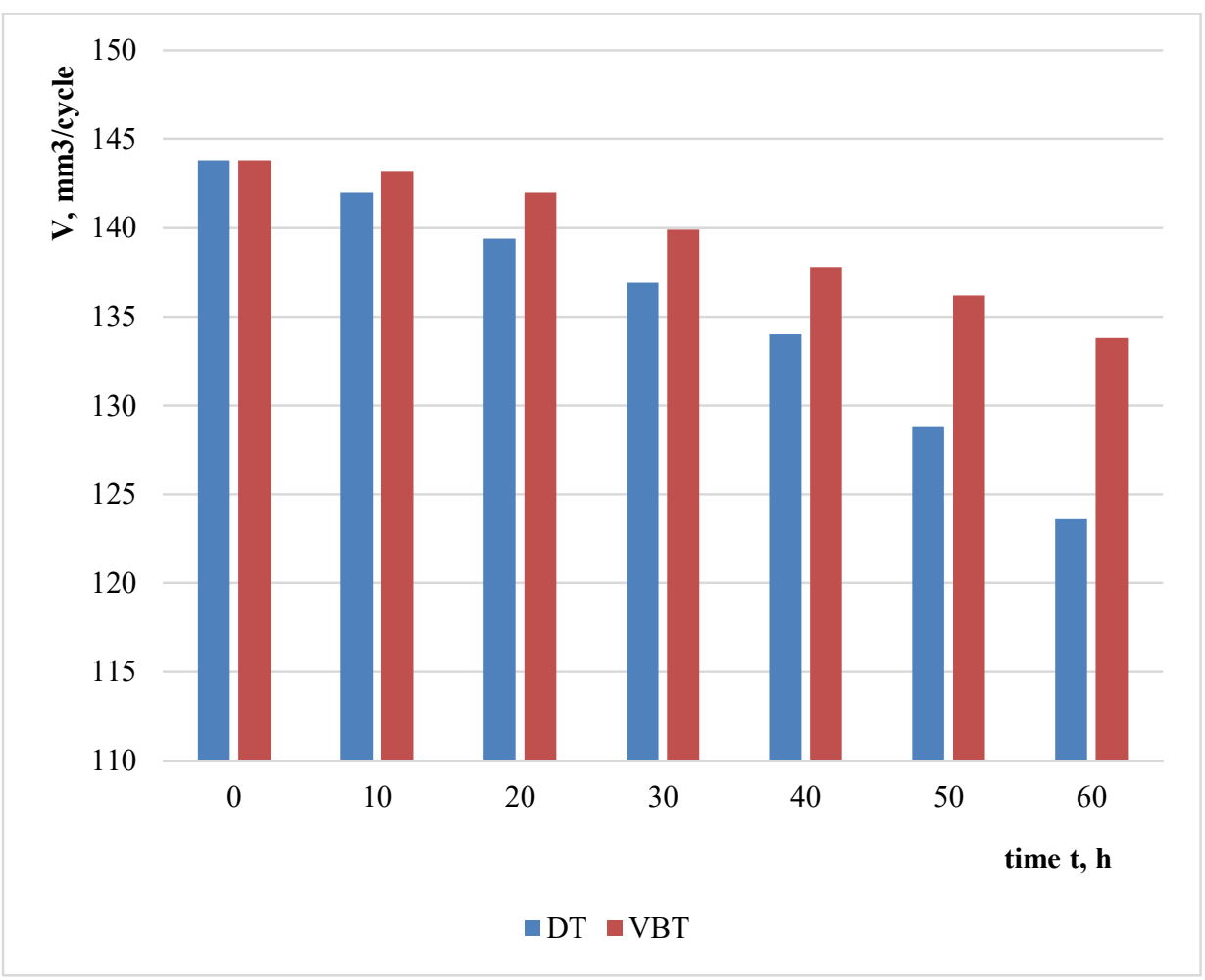

Fig. 2. Changing the cycle fuel supply at the nominal operating mode. 
During the tests, stable results are observed that can reliably determine the technical condition of the plunger pairs at the moment.

The dependence of the cyclic fuel supply on the time of the study (Fig. 1,2) at a low speed of the cam shaft of the high-pressure pump $\left(n=100 \mathrm{~min}^{-1}\right)$ and at nominal $(n=1100$ $\min ^{-1}$ ) was also revealed.

An increase in the cyclic supply of fuel causes a decrease in the duration of the increase in pressure. This agrees well with the theoretical considerations presented. It should be noted a sharp increase in the time of increase in pressure in the supraplunger cavity (decrease in the angle of increase in pressure) with a decrease in the hydraulic density of the plunger couples from $5 \mathrm{~s}$ to 0 , which takes place with significant wear.

According to the results of experimental studies, the possibility of diagnosing precision TA units by changing the cyclic feed during diesel acceleration from minimum to maximum crankshaft revolutions was confirmed. Diagnostic parameters and their values for precision TA units with in-line injection pumps have been determined. Based on the results obtained, algorithms were developed for extracting diagnostic information of precision nodes.

\section{Conclusions}

1. The method of calculating the flow of fuel through leaks in the plunger pair that characterize wear provides sufficient accuracy for practical purposes.

2. The mathematical model of fuel supply processes can be used for practical purposes.

3. Accelerated wear tests of fuel equipment have shown that when using water biofuels, the intensity of reducing the cyclic fuel supply decreases.

\section{References}

1. A. Altybayev, A. Zhanbyrbayev, B. Meskhi, D. Rudoy, A. Olshevskaya, A. Prohorova, E3S Web of Conferences 135, 01078

(2019) https://doi.org/10.1051/e3sconf/201913501078

2. B. Meskhi, B. Golev, V. Efros, D. Rudoy, A. Olshevskaya, V. Zhurba, Y. Chayka, E3S Web of Conferences 135, 01083 (2019) https://doi.org/10.1051/e3sconf/201913501083

3. J. Gerber, A. Zavaly, A. Gavrilov, A. Olshevskaya, N. Kiyan, IOP Conf. Series: Earth and Environmental Science 403, 012014 (2019) doi:10.1088/1755-1315/403/1/012014

4. G. Parkhomenko, S. Kambulov, A. Olshevskaya, A. Babadzhanyan, N. Gucheva, I. Mekhantseva, IOP Conf. Series: Earth and Environmental Science 403, 012144 (2019) doi:10.1088/1755-1315/403/1/012144

5. S.N. Kazantsev, V.V. Loginov, E.V. Sviridov, Modernization and research in the transport complex 1, $108-110$ (2014)

6. S.I. Kambulov, I.V. Bozhko, A.V. Olshevskaya, MATEC Web of Conferences 224, 05022 (2018) https://doi.org/10.1051/matecconf/201822405022

7. Y. Lachuga, A. Soloviev, A. Matrosov, I. Panfilov, V. Pakhomov, D. Rudoy, IOP Conf. Series: Earth and Environmental Science 403, 012055 (2019) doi:10.1088/1755$1315 / 403 / 1 / 012055$

8. S.I. Kambulov, I.V. Bozhko, A.V. Olshevskaya, MATEC Web of Conferences 224, 05022 (2018) https://doi.org/10.1051/matecconf/201822405022

9. Z. Dabrowski, M. Zawisza, Diffusion and Defect Data Pt.B 180, 194-199 (2012) 
10. S.N. Shukhanov, A.V. Kuzmin, P.A. Boloev, Proceedings of the Orenburg state agrarian University 1(75), 74 - 75 (2019)

11. T.V. Bodyakina, T.P. Gergenova, P.A. Boloev, Messenger Of ISAA 81/1, 63-67 (2017)

12. Y. Lachuga, A. Soloviev, A. Matrosov, I. Panfilov, V. Pakhomov, D. Rudoy, IOP Conf. Series: Earth and Environmental Science 403, 012055 (2019) doi:10.1088/17551315/403/1/012055

13. E. Zubrilina, I. Markvo, V. Novikov, A. Beskopylny, L. Vysochkina, D. Rudoy, A. Butovchenko, IOP Conf. Series: Earth and Environmental Science 403, 012063 (2019) doi:10.1088/1755-1315/403/1/012063

14. A.T. Lebedev, P.A. Lebedev, Tractors and agricultural machines 7, 43-45 (2011)

15. K. Antosz, IFAC-Papers On Line 49-12, 1389-1393 (2016)

16. P.I. Ilyin, Actual problems of agricultural science 28, 5-14 (2018)

17. N.P. Kodintsev, Aktual'nye problemy gumanitarnykh i estestvennykh nauk, 16-18 (2016)

18. L.B. Leont'ev, A.L. Leont'ev, Sudostroenie 3, 40-41 (2011)

19. Z.A. Samatov, S.N. Sharifullin, N.N. Adigamov, N.N. Adigamov, Sovremennye problemy nauki i obrazovaniya 3 (2014) https://www.scienceeducation.ru/ru/article/view?id=13062 